\title{
Knowledge and attitude of medical undergraduate, interns and postgraduate students towards emergency contraception
}

\author{
Amisha Dogra*, Uma N. Wankhede
}

Department of Obstetrics and Gynecology, BJGMC and SGH Pune, Maharashtra, India

Received: 24 April 2017

Accepted: 22 May 2017

\section{*Correspondence:}

Dr. Amisha Dogra,

E-mail: amishadogra99@gmail.com

Copyright: (C) the author(s), publisher and licensee Medip Academy. This is an open-access article distributed under the terms of the Creative Commons Attribution Non-Commercial License, which permits unrestricted non-commercial use, distribution, and reproduction in any medium, provided the original work is properly cited.

\begin{abstract}
Background: Although India was the first country in the world to have national family planning policy, the acceptance of contraceptive methods has been unsatisfactory. Many women in their peak reproductive years, who wish to control their fertility, are not aware about the different methods of contraceptives available. Unregulated fertility results in unplanned pregnancies. Emergency contraceptive pills can avoid many such unplanned pregnancies. The study was to assess the knowledge and attitude about emergency contraception (EC) among the undergraduate, interns and postgraduate medical science university students.

Methods: A cross sectional study was carried out among 180 medical students which include undergraduate, interns, and postgraduate students (60 from each group) studying at BJ Medical College, Pune, Maharashtra by a convenient sample method over a period of August 2016 to November 2016. Data were collected by pre-designed, pre-tested, self-administered questionnaire. Data was analyzed in the form of percentage and proportions and Chi square test was applied.

Results: In this study, a total of 180 respondents, of which $110(61.2 \%)$ were male and $70(38.8 \%)$ were female. The knowledge about EC was highest (47.6\%) among postgraduates in comparison to interns (43.3\%) and undergraduate students $(41.6 \%)$. Overall positive attitude toward EC was observed among $73.8 \%$ of the respondents.

Conclusions: Considering the role of a medical graduate as counselor and health care provider, the technical knowledge about different aspects of EC among the study population was inadequate.
\end{abstract}

Keywords: Attitude, Contraception, Knowledge, Students

\section{INTRODUCTION}

Despite the availability of highly effective methods of contraception, many pregnancies remain unplanned and unintended. Many of these pregnancies can be avoided by the use of emergency contraception (EC). ${ }^{1}$ EC (or postcoital) pills defined as the use of a drug or a device to prevent pregnancy after unprotected sexual intercourse, has been shown to be safe and effective. ${ }^{2}$ Emergency contraceptive pills (ECPs) have been available since 1960s, but service delivery protocol were not standardized, and many providers did not know about this method and access has been limited. ${ }^{3}$ Yuzpe regimen of combined oral contraceptive pills for EC has been added to the WHO model list of essential drugs and included in new list of seven high priority leads of reproductive health program. ${ }^{4}$ The Department of Family Welfare of India has already decided to promote ECPs in the National reproductive child health programme to achieve the National population policy goals. ${ }^{5}$ EC is the only method that can be used to prevent pregnancy after unprotected sex or contraceptive accident. Therefore, 
women should know about these methods before the need arises. ${ }^{6}$

In India, studies on EC have been done among adult married women. However, the level of knowledge among the medical student population about EC has not been adequately investigated. The medical students/interns are the doctors in making, who hold the promise of providing health-care services to the community in near future.

With this in mind, the present study was conducted to explore knowledge of and attitude about EC among undergraduate, interns and postgraduate students of BJ Medical College Pune.

\section{METHODS}

A cross-sectional study was carried out among 180 medical students from undergraduates (final year MBBS), interns, and postgraduates (60 from each group) studying and working at BJ Medical college, Pune by a convenient sample method over a period of 4 months from August 2016 to November 2016.

A pre-designed, self-administered questionnaire in English was devised to collect data. The demographic details like age, gender, and marital status of the respondents were also recorded. A 12-item questionnaire was constructed to assess knowledge about EC, based upon a review of literature and similar studies conducted elsewhere. Some questions were objective in nature with 'yes' or 'no' options whereas a few questions were multiple-choice. Each correct answer was given 1 score and the range of the score varied between 0 (with incorrect answer) and 12 (for all correct answers). A scoring mechanism was used to understand the overall knowledge level; a score of one was given for each correct response and zero for each wrong response. Respondents with all correct responses get a maximum of 12 points, and higher points indicate good knowledge. Based on total score, knowledge level on EC was categorized into poor ( $\leq 4$ points), average (5-8 points), and good ( $\geq 9$ points). Questions which were assessing the attitude included four questions with "yes," and "no" options. Using this two-point scale for four questions, we arbitrarily set the maximum score for each respondent at eight and the minimum at two.

We decided that a high score was indicative of positive attitude whereas a low score would be indicative of a negative attitude. The participation to study was on voluntary basis. All the participants were given a briefing about objective of the study and assured confidentiality in collection of personal data.

\section{Statistical study}

Data were entered into Microsoft Excel and analyzed using the Statistical Package of Social Sciences (SPSS) version-13.0. Statistical significance was set at $\mathrm{P} \leq 0.05$.

\section{RESULTS}

The demographic characteristics of the study population are shown in Table 1 . The study sample consisted of 110 $(61.2 \%)$ men and $70(38.8 \%)$ women. Majority (89.4\%) of the respondents were unmarried.

Table 1: Demographic characteristics of the study population.

\begin{tabular}{|lll|}
\hline Demographic characteristics & No. $(\mathbf{n}=180)$ & $\%$ \\
\hline Gender & & \\
\hline Male & 110 & 61.2 \\
\hline Female & 70 & 38.8 \\
\hline Age in years (mean SD) & & \\
\hline Undergraduates & $22.1(2.3)$ & \\
\hline Interns & $23.3(2.4)$ & \\
\hline Postgraduates & $25.5(2.7)$ & \\
\hline Marital status & & 10.6 \\
\hline Married & 19 & 89.4 \\
\hline Unmarried & 161 & \\
\hline
\end{tabular}

In this study, $100 \%$ of the respondents were aware about EC. The overall good level of knowledge about EC was highest $(47.6 \%)$ among postgraduates in comparison to interns $(43.3 \%)$ and undergraduate students (41.6\%) (Table 2). A statistically significant association was observed between EC knowledge and respondents from each group.

The attitude toward EC was measured through four questions; the questions were related on respondent's attitude toward the paramedical staff that dispenses EC, Is EC good for women's reproductive health, Is ECPs would discourage the consistent use of condom, and Is EC safe for its users (Table 3). Overall positive attitude towards EC was observed among $73.8 \%$ of the respondents. Student's category-wise results showed that $75 \%$ of postgraduate, $80 \%$ of interns and $66.7 \%$ of undergraduate students had expressed positive attitude. Also, there is no statistical difference of attitude toward EC between the three groups.

\section{DISCUSSION}

In India, despite a National Family Welfare Programme and widespread efforts by the government, the rates of unplanned pregnancies and illegal abortions are high. It is estimated that $78 \%$ pregnancies are unplanned and $25 \%$ are definitely unwanted. ${ }^{6}$ The number of unsafe abortions has also been increasing despite legalization of abortion in India through MTP Act 1971. In the present study, about one-fourth of the respondents $(25.5 \%)$ thought EC is an abortifacient, compared to $25.8 \%$ of university students in Ghana, $51.2 \%$ of university students in Cameroon, $49 \%$ of nursing students in Kenya, $25 \%$ of doctors in the Pakistan, and $8.1 \%$ of doctors in Delhi. ${ }^{7-11}$ Only $46.1 \%$ of the respondents correctly chose menstrual irregularity not being most common side-effect. This was similar to the findings of a study by Abdulghani et al. ${ }^{10}$ 
Table 2: Knowledge about emergency contraception among study population.

\begin{tabular}{|c|c|c|c|c|}
\hline Questions on knowledge & $\begin{array}{l}\text { Undergraduates } \\
(n=60) \text { correct } \\
\text { response }\end{array}$ & $\begin{array}{l}\text { Interns } \\
\text { ( } \mathrm{n}=60 \text { ) correct } \\
\text { response }\end{array}$ & $\begin{array}{l}\text { Postgraduates } \\
{[n=60] \text { correct }} \\
\text { response }\end{array}$ & P value \\
\hline Who is the ideal candidate for EC? & $38(63.4)$ & $44(73.4)$ & $51(85)$ & 0.026 \\
\hline $\begin{array}{l}\text { Maximam acceptability time after sex for woman } \\
\text { to take EC? }\end{array}$ & $50(83.4)$ & $52(86.7)$ & $57(95)$ & 0.012 \\
\hline $\begin{array}{l}\text { Do you know about methods of emergency } \\
\text { contraception? }\end{array}$ & $35(58.4)$ & $45(75.0)$ & $50(83.4)$ & 0.008 \\
\hline Does EC act as abortifacient? & 37 (61.7) & $45(75)$ & $52(86.7)$ & 0.007 \\
\hline Do you know mechanism of action of EC? & $42(70)$ & 47 (78.4) & $39(65)$ & 0.266 \\
\hline Is EC easily purchased from retail outlets? & $25(41.7)$ & $32(53.4)$ & $40(66.7)$ & 0.023 \\
\hline $\begin{array}{l}\text { Is menstrual irregularity most common side effect } \\
\text { of EC? }\end{array}$ & $18(30.0)$ & $30(50)$ & $35(58.4)$ & 0.006 \\
\hline Does EC provide protection against STD and RTI? & $48(80)$ & $50(83.4)$ & $57(95)$ & 0.045 \\
\hline Is pregnancy test necessary before prescribing EC? & $32(53.4)$ & $36(60)$ & $39(65)$ & 0.426 \\
\hline Does efficacy of EC reduce by passing hour? & $27(45)$ & $33(55)$ & $36(60)$ & 0.245 \\
\hline Does EC available free of cost at govt. centers? & $21(35)$ & $28(46.7)$ & $34(56.7)$ & 0.058 \\
\hline After fertilization IUCD effective as EC? & $24(40)$ & $31(51.7)$ & $38(63.4)$ & 0.038 \\
\hline
\end{tabular}

EC-Emergency contraceptive, STD-Sexually transmitted diseases, RTI-Reproductive tract infection, IUCD-Intrauterine contraceptive device. Figures in bracket indicate percentage.

Knowledge about the correct time for taking ECPs after unprotected sex was $(88.3 \%)$ in this study. This finding is higher than $11.3 \%$ reported in Ghana, and $5.7 \%$ reported in the Cameroon study. ${ }^{7,8}$ In our study, $28.9 \%$ respondents did not have an accurate knowledge of the mechanism of action of an EC. This was similar to the findings of a study by Singh et al. ${ }^{11}$ Only $13.9 \%$ were not sure whether ECs protect from sexually transmitted diseases/reproductive tract infections (STDs/RTIs). This was in contrast to a study done by Parey et al. ${ }^{12}$ Who showed that $94.8 \%$ were not sure whether ECs protect from STDs/RTIs.

Table 3: Participant's attitude about emergency contraception.

\begin{tabular}{|c|c|c|c|c|}
\hline Questions on attitude & Undergraduate $(n=60)$ & Interns $(n=60)$ & Postgraduates $(n=60)$ & P value \\
\hline \multicolumn{5}{|c|}{ Should paramedical staff dispense EC? } \\
\hline Yes & $26(43.4)$ & $15(25)$ & $18(30)$ & 0.874 \\
\hline No & $34(66.6)$ & $45(75)$ & $42(70)$ & \\
\hline \multicolumn{5}{|c|}{ Is EC good for woman reproductive health? } \\
\hline Yes & $24(40)$ & $27(45)$ & $21(35)$ & 0.535 \\
\hline No & $36(60)$ & $33(55)$ & $39(65)$ & \\
\hline \multicolumn{5}{|c|}{ Is ECPs would discourage consistent use of condoms } \\
\hline Yes & $20(33.3)$ & $12(20)$ & $15(25)$ & 0.244 \\
\hline No & $40(66.7)$ & $48(80)$ & $45(75)$ & \\
\hline \multicolumn{5}{|l|}{ Is EC safe for its users } \\
\hline Yes & $38(63.3)$ & $45(75)$ & $41(68.3)$ & 0.383 \\
\hline No & $22(36.7)$ & $15(25)$ & $19(31.7)$ & \\
\hline
\end{tabular}

EC-Emergency contraceptive, Figures in bracket indicate percentage.

Although our respondents generally held favorable opinions about ECPs, most of them believed that ECPs were safe for their users. Similar findings have been reported by other authors. ${ }^{7,8,13}$ About $26.1 \%$ participants thought providing ECPs would discourage the consistent use of condoms compared to $53.4 \%$ of students in Ghana and $38.4 \%$ of university students in Cameroon. ${ }^{7,8}$ Participants agreed that EC should be sold only on prescription and about $67.2 \%$ discouraged its distribution by paramedical staff. This was similar to the findings of a study by Singh et al. ${ }^{11}$ Who revealed that $65 \%$ of doctors agreed that EC should be sold only on prescription and more than half discouraged its distribution by paramedical staff. Majority $(60 \%)$ of the respondents did not agree that EC is good for women's reproductive health. Similarly, a study done by Parey et al also found that $75.8 \%$ of the participants thought that ECs were harmful to the body. ${ }^{12}$

Limitations of the study was the use of a convenient sample. It limited the generality and ability of the study. In addition, it is important to remember that the results of 
this study are dependent upon the accuracy of the responses.

\section{CONCLUSION}

This study suggested that participants had overall positive attitude toward EC, but lacked correct knowledge. Knowledge about effectiveness, mechanism, and specific information regarding protection from STDs/RTIs was lacking. So, there is a need to further educate them about EC. The medical curriculum must be updated regularly about the newer methods of contraceptives so that the community at large gets benefited.

\section{Funding: No funding sources}

Conflict of interest: None declared

Ethical approval: Not required

\section{REFERENCES}

1. Trussell J, Koenig J, Ellertson C, Stewart F. Preventing unintended pregnancy: The costeffectiveness of three methods of emergency contraception. Am J Public Health. 1997;87:932-7.

2. Fornari A, Fletcher J, Herbitter C, Boden L, Gold M. Students as patients and teachers: Evaluation of an experiential emergency contraception project. Fam Med. 2011;43:172-8.

3. WHO Task force on postovulatory methods of fertility regulation. Randomized controlled trial of levonorgestrel versus Yuzpe regimen of combined oral contraceptives for emergency contraception. Lancet. 1998;352:428-33.

4. Emergency contraception: A Guide for service delivery. Geneva: WHO; World Health Organization; 1988;60-2.

5. Department of Family Welfare, Ministry of Health and Family Welfare, Govt. of India;. Dec, Guidelines for administration of ECPs for medical officers, Research studies and standard division; 2002:3-5.

6. Puri S, Bhatia V, Swami HM, Singh A, Sehgal A, Kaur AP. Awareness of emergency contraception among female college students in Chandigarh, India. Indian J Med Sci. 2007;61:338-46.

7. Baiden F, Awini E, Clerk C. Perception of university students in Ghana about emergency contraception. Contraception. 2002;66:23-6.

8. Kongnyuy EJ, Ngassa P, Fomulu N, Wiysonge CS, Kouam L, Doh AS. A survey of knowledge, attitudes and practice of emergency contraception among university students in Cameroon. BMC Emerg Med. 2007;7:7.

9. Muia E, Ellertson C, Lukhando M, Flul B, Clark S, Olenja J. Emergency contraception in Nairobi, Kenya: Knowledge, attitudes and practices among policymakers, family planning providers and clients, and university students. Contraception. 1999;60:22332.

10. Abdulghani HM, Karim SI, Irfan F. Emergency contraception: Knowledge and attitudes of family physicians of a teaching hospital, Karachi, Pakistan. J Health PopulNutr. 2009;27:339-44.

11. Singh S, Mittal S, Anandalakshmy PN, Goel V. Emergency contraception: Knowledge and views of doctors in Delhi. Health Popul Perspect Issues. 2002;25:45-54.

12. Parey B, Addison L, Mark JK, Maurice B, Tripathi V, Wahid S, et al. Knowledge, attitude and practice of emergency contraceptive pills among tertiary level students in Trinidad: A cross-sectional survey. West Indian Med J. 2010;59:650-5.

13. Harper CC, Ellertson CE. The emergency contraceptive pill: A survey of knowledge and attitudes among students at Princeton University. Am J Obstet Gynecol. 1995;173:1438-45.

Cite this article as: Dogra A, Wankhede UN. Knowledge and attitude of medical undergraduate, interns and postgraduate students towards emergency contraception. Int J Reprod Contracept Obstet Gynecol 2017;6:2944-7. 